\title{
REMARKS ON THE PAPER "A NOTE ON EVERITT TYPE INTEGRAL INEQUALITY" OF B. G. PACHPATTE
}

\author{
DRAGOSLAV S. MITRINOVIĆ AND JOSIP E. PEČARIĆ
}

\begin{abstract}
In the present note we give an interpolating inequality for Pachpatte's inequality from [1]. A discrete analogouos is also given.
\end{abstract}

B. G. Pachpate [1] proved the following theorem:

Theorem $\mathbb{A}$. Let $p, q$ be real-valued continuous functions defined on $I=[a, b] ; p^{\prime}$ exists and is continuous on $I$. Let $f, g$ be real-valued continuous functions defined on $I$ which are twice continuously differentiable on $I$ and $f(a)=f(b)=g(a)=g(b)=0$. Then

$$
\begin{aligned}
& \left(\int_{a}^{b}\left[p(t) f^{\prime}(t) g^{\prime}(t)+q(t) f(t) g(t)\right] d t\right)^{2} \\
& \quad \leq \frac{1}{2}\left\{\left(\int_{a}^{b} M[f(t)]^{2} d t\right)\left(\int_{a}^{b} g^{2}(t) d t\right)+\left(\int_{a}^{b} M[g(t)]^{2} d t\right)\left(\int_{a}^{b} f^{2}(t) d t\right)\right\},
\end{aligned}
$$

where

$$
M[f(t)]=-\left(p(t) f^{\prime}(t)\right)^{\prime}+q(t) f(t) .
$$

Equality holds in (1) if either $f$ is null or $g$ is null on $I$.

Here we shall note that the following interpolation inequality for (1) is valid:

If the conditions of Theorem $\mathrm{A}$ are valid then

$$
\begin{aligned}
\left(\int_{a}^{b}\left[p(t) f^{\prime}(t) g^{\prime}(t)+q(t) f(t) g(t)\right] d t\right)^{2} . \\
\quad \leq\left\{\left(\int_{a}^{b} M[f(t)]^{2} d t\right)\left(\int_{a}^{b} g^{2}(t) d t\right)\left(\int_{a}^{b} M[g(t)]^{2} d t\right)\left(\int_{a}^{b} f^{2}(t) d t\right)\right\}^{1 / 2} \\
\quad \leq \frac{1}{2}\left\{\left(\int_{a}^{b} M[f(t)]^{2} d t\right)\left(\int_{a}^{b} g^{2}(t) d t\right)+\left(\int_{a}^{b} M[g(t)]^{2} d t\right)\left(\int_{a}^{b} f^{2}(t) d t\right)\right\} .
\end{aligned}
$$

As in [1] we have

$$
\begin{aligned}
& \int_{a}^{b} p(t) f^{\prime}(t) g^{\prime}(t) d t=-\int_{a}^{b}\left(p(t) f^{\prime}(t)\right)^{\prime} g(t) d t \\
& \int_{a}^{b} p(t) f^{\prime}(t) g^{\prime}(t) d t=-\int_{a}^{b}\left(p(t) g^{\prime}(t)\right)^{\prime} f(t) d t .
\end{aligned}
$$

Received April 7, 1989. 
From (3) and (4) we observe that

$$
\begin{aligned}
& \left(\int_{a}^{b}\left[p(t) f^{\prime}(t) g^{\prime}(t)+q(t) f(t) g(t)\right] d t\right)^{2} \\
& \quad=\left(\int_{a}^{b} M[f(t)] g(t) d t\right)\left(\int_{a}^{b} M[g(t)] f(t) d t\right) .
\end{aligned}
$$

Using Cauchy's inequality to each integral on the right side we obtain the first inequality in (2). The second inequality in (2) is a simple consequence of the arithmetic mean-the geometric mean inequality.

Similarly, we can prove discrete analogous of the previous results. For example the following result is valid:

Let $a, b, p, q$ be real $n$-tuples, and let $\Delta$ and $M_{n}$ be operators defined by

$$
\Delta a_{i}=a_{i+1}-a_{i}, M_{i}(a)=-\Delta\left(p_{i-1} \Delta a_{i-1}\right)+q_{i} a_{i}
$$

If $a_{1}=a_{n}=b_{1}=b_{n}=0$, then we have

$$
\begin{aligned}
& \left(\sum_{i=1}^{n-1}\left(p_{i} \Delta a_{i} \Delta b_{i}+q_{i} a_{i} b_{i}\right)\right)^{2} \leq\left\{\sum_{i=1}^{n} a_{i}^{2} \sum_{i=1}^{n} b_{i}^{2} \sum_{i=2}^{n-1} M_{i}(a)^{2} \sum_{i=2}^{n-1} M_{i}(b)^{2}\right\}^{1 / 2} . \\
& \text { Reference }
\end{aligned}
$$

[1] B. G. Pachpatte, "A Note on Everitt Type Integral Inequality." Tamkang Journal of Mathematics Vol. 18, No. 2, 1987, pp. 7-10.

Smiljaniceva, 11000 Beograd, Yugoslavia.

Faculty of Technology, Ive Lole Ribara 126, 41000 Zagreb, Yugoslavia. 